\title{
Cultural and Situational Contingencies and the Theory of Reasoned Action: Application to Fast Food Restaurant Consumption
}

\author{
Richard P. Bagozzi \\ School of Business \\ University of Michigan \\ Nancy Wong \\ Department of Marketing \\ University of Hawaii \\ Shuzo Abe \\ Faculty of Business Administration \\ Yokohama National University \\ Massimo Bergami \\ Department of Business Economics \\ University of Bologna
}

\begin{abstract}
This study investigated the usefulness of the theory of reasoned action for fast food restaurant patronage decisions. The theory of reasoned action was found to generalize across four samples drawn from the United States $(N=246)$, Italy $(N=123)$, The People's Republic of China $(N=$ $264)$, and Japan $(N=419)$. However, predictions under the theory of reasoned action were found to vary, depending on the social setting (eating alone or eating with friends) and cultural orientation (independent vs. interdependent). Among other results, subjective norms were found to influence decisions when eating with friends, but not when alone; the effects of attitudes, subjective norms, and past behavior on intentions were greater for Americans than Italians, Chinese, or Japanese; and in general, more explained variance occurred for Western (American, Italian) than Eastern (Chinese, Japanese) cultures.
\end{abstract}

The theory of reasoned action (TRA), a model of the determinants of volitional behavior, maintains that behavior is directly influenced by intentions to act, and, in turn, intentions to act are determined by one's attitude toward the act and felt subjective norm that one should act (Ajzen \& Fishbein, 1980). Consumer researchers have applied the TRA to a wide variety of behaviors over the years, including the consumption of automobiles, banking services, computer software, coupons, detergents, and soft drinks, among many others

Requests for reprints should be sent to Richard P. Bagozzi, School of Business, University of Michigan, Ann Arbor, MI 48109-1234. E-mail: bagozzi@umich.edu (e.g., Lutz, 1977; Ryan \& Bonfield, 1980; Sheppard, Hartwick, \& Warshaw, 1988).

One unanswered question is, to what extent does the TRA apply to consumption behaviors in other cultures? Although the TRA has been applied extensively within North America and to a lesser extent within various cultures around the world, few cross-cultural studies examining the boundary conditions and generalizability of the TRA in consumption settings can be found (cf. Lee \& Green, 1991). Indeed, it appears that little is known about the generalizability of the TRA in general, as witnessed by the conspicuous lack of discussion on cross-cultural applications in basic attitude texts (e.g., Eagly \& Chaiken, 1993) and in cross-cultural psychology books (e.g., Berry, Poortinga, Segall, \& Dasen, 1992; 
Matsumoto, 1996; Triandis, 1994a). Thus, one purpose of this study was to investigate issues of generalizability of the TRA, especially for consumption acts.

A second issue concerned the role of subjective norms. Unlike attitudes, which consistently relate to intentions in empirical research and thus accord well with predictions under the TRA, subjective norms have frequently failed to predict intentions in consumer research as well as does research into more general everyday behaviors. We examine in this study how two situational conditions relate to subjective normative influence.

Finally, this study tested the TRA while controlling for past behavior, and it looked at behavioral expectations as criteria, along with intentions. These and the aforementioned issues are developed further in the next section of the article.

\section{HYPOTHESES}

\section{Subjective Norms}

Subjective norms reflect a person's belief about whether people to whom one is close or whom one respects think that he or she should perform a particular act (Ajzen \& Fishbein, 1980). The influence of subjective norms is presumed to capture the social pressure a decision maker feels to make a purchase or not.

In this study, we hypothesized that subjective normative influence would be a function of the degree of peer pressure one experiences. We manipulated the degree of peer pressure by varying the social context of consumption. As a setting for testing hypotheses, we chose fast food restaurant patronage. For each of the variables in the TRA, people were asked to express their reactions to eating alone and eating with friends at a fast food restaurant. To the extent that decisions are dependent on peer pressure, we expected the effect of subjective norms on intentions to eat in fast food restaurants to be stronger for eating with friends than for eating alone.

\section{Culture as a Category}

To investigate the generalizability and the differences in predictions under the TRA, we chose to test hypotheses for consumers from independent- and interdependent-based cultures. Markus and Kitayama (1991) proposed the distinction between independent and interdependent selves or self-concepts to explain cultural differences in cognitive, emotional, and motivational aspects of behavior.

The independent self-concept is common in many Western cultures and is characterized by an emphasis on personal goals, personal achievement, and appreciation of one's differences from others. People with an independent self-concept tend to be individualistic, egocentric, autonomous, self-reliant, and self-contained. They place consider- able importance on asserting the self and are driven by self-serving motives. The individual is the primary unit of consciousness, with the self coterminous with one's own body. Relationships with others frequently serve as standards of self-appraisal, and the independent self takes a strategic posture vis-à-vis others in an effort to express or assert one's internal attributes. One's personal attributes are primary and are seen as relatively stable from context to context. Emphasis is placed on displaying or showing one's attributes or internal states (e.g., pride, anger). The normative imperative is to become independent from others and discover one's uniqueness.

The interdependent self-concept is common in many non-Western cultures and is characterized by stress on goals of a group to which one belongs, attention to fitting in with others, and appreciation of commonalities with others. People with an interdependent self-concept tend to be obedient, sociocentric, holistic, connected, and relation oriented. They place much importance on social harmony and are driven by other-serving motives. The relationships one has are the primary unit of consciousness, with the self coterminous with either a group or the set of roles one has with individuals in the family or relevant group, such as an organization. Relationships with others are ends in and of themselves, and the interdependent self takes a stance vis-à-vis others of giving and receiving social support. One's personal attributes are secondary and are allowed to change as needed in response to situational demands. Emphasis is placed on controlling one's attributes or internal states (e.g., avoiding displaying anger publicly). The normative imperative is to maintain one's interdependence with others and contribute to the welfare of the group.

\section{Cultural Variation}

Triandis (1994a) argued that one of the four defining attributes of individualism and collectivism is the relative importance of attitudes versus norms as determinants of social behavior. For collectivists, the determinants of social behavior are primarily norms, duties, and obligations, whereas for individualists, they are primarily attitudes, personal needs, perceived rights, and contracts (Miller, 1994; Triandis \& Bhawuk, 1997). Because the TRA was developed in the United States, an independent-based culture, and at the same time emphasizes variables focusing on internal states, we would expect it to apply more fully to Western cultures than to Eastern cultures. For hypotheses based on the predicted relationships within the TRA, we expected (except for the following case) that the magnitude of effects on intentions and behavioral expectations would be greater for Western (especially the United States) cultures than Eastern cultures. Similarly, we expected more variation to be explained in the dependent variables for Western than for Eastern cultures. Finally, the one exception to the aforementioned predictions 
was expected to occur for the effects of subjective norms, the only variable in the TRA designed to reflect some social content in decision making.

We hypothesized that the magnitude of effects for subjective norms on intentions and behavioral expectations to be greater in Eastern than Western cultures. Support for this latter hypothesis can be seen in Lee and Green (1991), who found in a study of the purchase of sneakers that subjective norms had no effect on intentions for Americans $(\gamma=.06, n s)$ and a strong effect for Koreans $(\gamma=.52, p<.001)$. Further support for cross-cultural variations of attitude-behavior consistency can be found in Bontempo and Rivero's (1990) meta-analysis of cross-cultural studies of the TRA. They found that individualists' behavior is more closely linked to attitudes, and collectivists' behavior is more closely linked to norms (Triandis, 1994b, p. 49). Trafimow and Finlay (1996) discovered in their study of American student participants that behavioral intentions were more controlled by attitudes than subjective norms in 29 out of 30 behavioral situations. However, they also found that subjective norms still accounted for a small but significant portion of unique variance in behavioral intentions. In particular, they found two groups of individuals, people who are more under attitudinal versus normative control in their behaviors and vice versa. The former were labeled attitudinal controlled, whereas the latter were called normatively controlled individuals. Trafimow and Finlay (1996) further learned that this individual difference was associated with the strength of respondents' collective self. This finding is consistent with Triandis's (1989, 1994a, 1994b) earlier thesis that individuals with a strong collective self are more likely than individuals with a strong individualist self to behave in accordance with the opinions of those who are important to them. This is also consistent with findings in Lee and Green (1991) that Korean consumers' purchase intentions were predicted by subjective norms, whereas those of American consumers were predicted by attitudes toward the behavior.

However, it is important to stress that Trafimow and Finlay's (1996) findings were based on American participants alone, whereas Lee and Green's (1991) study did not account for individual differences in self-construals. Furthermore, neither of these studies looked at differences across situations. Therefore, a goal of this study was to disentangle the effects of culture and situations in testing the relative importance of attitudes and subjective norms on behavioral intentions (Brockner \& Chen, 1996).

\section{Situational Variation}

Although the attitudes to intentions and the subjective norms to intentions consistencies have been shown in previous research to vary across situations, the test of the interaction effect between culture and situation has not been established. Trafimow, Triandis, and Goto (1991) showed that people from independent-self cultures retrieved more private-self cognitions, whereas people from interdependent-self cultures retrieved more collective-self cognitions. Therefore, an additional contribution of this study was to test for any incremental effect of culture (i.e., collective self) on the subjective norms to intentions relation, within the same social context of eating with friends.

The aforementioned hypotheses address relations between variables in the TRA. For hypotheses based on differences in mean levels of the variables in the TRA across Western and Eastern cultures, we predicted the following: We hypothesized that the level of attitudes, past behavior, and intentions would be greater, and the levels of behavioral expectations and subjective norms would be less, for Western (especially American), as opposed to Eastern, cultures. These predictions follow the cultural distinctions implied in independent versus interdependent self-concepts (Markus \& Kitayama, 1991). That is, the decision to eat alone, which is driven primarily by internal criteria of personal tastes and predispositions, should reveal stronger overall attitudes, intentions, and past behavior from Western (especially the United States) than from Eastern cultures because the former entails a stronger independent self-construal. The decision to eat with friends, which is driven primarily by social factors, should reveal stronger overall subjective norms and behavioral expectations for Eastern than for Western cultures (see the following).

To increase the number of replications and thereby build in more difficulty in disproving the null hypotheses, we selected consumers from four cultures: Two independent- and two interdependent-based cultures. Specifically, consumers in the United States, Italy, China, and Japan were surveyed.

\section{Behavioral Expectations}

Decisions in the TRA are represented by intentions. We followed the TRA in this regard, but also included behavioral expectations as dependent variables.

Fishbein and Ajzen (1975) originally defined intentions as "people's expectancies about their own behavior in a given setting" (p. 288) and operationalized intentions as the likelihood one intends to act. Warshaw and Davis (1985) criticized this perspective on the grounds that it does not capture the common sense notion of intentions held by most people. They proposed that intentions correspond most closely to whether a person has formulated conscious plans to act, and that one's expectations that he or she will act should be a better predictor of actual behavior because it takes into account one's intentions, abilities to act, and assessment of the situation that one must act in, in terms of impediments or facilitators of action.

Because decisions to eat in fast food restaurants are frequently made at a point in time significantly before action is to be taken, and, especially for the case of eating with others, situational conditions must often be anticipated, we decided to model both intentions and behavioral expectations as de- 
pendent variables. We predicted that more variation in expectations would be explained when eating alone than when eating with friends because the decision to eat alone is relatively more under one's own control than is eating with others. For eating alone versus eating with friends, one has more flexibility on when and where to eat, and the decision is driven relatively more by taste, convenience, and attitudinal factors (i.e., internal considerations). Expectations about eating alone should be a strong function of internal reactions and do not need to take into account coordination with other people. Eating with friends in the future entails social and timing contingencies, for which one is less accurately able to forecast. Hence, the internal reactions of felt attitudes and subjective normative pressure are hypothesized to better predict expectations to eat in fast food restaurants when eating alone versus eating with friends.

We also predict that the explained variance in intentions should be greater than the explained variance in expectations for eating alone, and the explained variance in intentions should be less than the explained variance in expectations for eating with friends. When eating alone, one's internal states (e.g., attitudes) should be relatively more determinative of decisions, and volitions should be a greater function of these than are behavioral expectations, which are the resultant of internal as well as external forces. When eating with friends, the internal states have relatively less salience and expectations better capture one's judgment of the likelihood of subsequent behavior.

\section{Past Behavior}

To provide a more stringent test of the TRA, we included past behavior as a copredictor of intentions and behavioral expectations. One of the benefits of doing this is that it provides a fuller explanation of the dependent variables. That is, the effects of past behavior may capture automatic activation of intentions and expectations, such as reflected in "habit, or more generally, by various types of conditioned releasers or learned predispositions to respond"' (Eagly \& Chaiken, 1993, p. 178). The effects of attitudes and subjective norms reflect the results of more deliberative processing. We caution that the presumed effects of past behavior are only proxies for the underlying processes, which ultimately deserve more direct representation (cf. Ajzen, 1988).

The main benefit of including past behavior as a copredictor is methodological: "past behavior can be used to test the sufficiency of any model" (Ajzen, 1991, p. 202). That is, past behavior provides a control for at least some of the omitted variables. If we had found that attitudes and subjective norms influence intentions and behavioral expectations, even after controlling for past behavior effects, we would have achieved a stronger test of the TRA than had past behavior not been included (i.e., the standard formulation). Parallel to findings showing that past behavior reduces the effects of intentions on behavior (e.g., Bagozzi, 1981; Bentler \&
Speckart, 1979; Fredericks \& Dossett, 1983), we expected the impact of attitudes and subjective norms on intentions and behavioral expectations to be reduced after past behavior is introduced as a copredictor. This represents the control of automatic processes and permits a more stringent test of the effects of the more deliberative processes entailed by attitudes and subjective norms.

In addition, we predicted that past behavior would have greater impact on behavioral expectations than on intentions for both eating alone and eating with friends. This is because past behavior summarizes the effects of all reasons for acting in the past, whereas intentions capture only volitional reasons, and behavioral expectations reflect all reasons (Warshaw \& Davis, 1985). Again, we caution that past behavior is only a proxy for such effects, and ultimately more direct measures of the reasons for acting need to be obtained.

\section{METHOD}

\section{Participants}

Undergraduate students in four countries were surveyed. Initially, 246, 130, 419, and 275 students in the United States, Italy, Japan, and China, respectively, were asked to fill out a questionnaire. After discarding questionnaires containing incomplete responses, the final sample sizes were 246,123 , 419 , and 264 , respectively.

\section{Procedure}

Respondents were asked to provide answers to a questionnaire soliciting their opinions about fast food restaurants. Confidentiality of responses was assured, and indeed, participants were instructed not to sign or provide identifying marks on the questionnaire.

The back-translation procedure was used to prepare the questionnaire, as recommended by Brislin (1986). Questionnaire items were first prepared in English. Next, bilingual persons translated the items into Chinese, Italian, and Japanese. Then different bilingual persons translated the Chinese, Italian, and Japanese versions back into English. Finally, the few inconsistencies that resulted between translations were reconciled.

\section{Measures}

Attitudes were measured separately toward "eating at fast food restaurants by myself" and "eating at fast food restaurants with friends." In both cases, the time frame was specified as "during the next two weeks," and five 7-point, semantic, differential items were used: pleasant-unpleasant, wise-foolish, attractive-unattractive, beautiful-ugly, and rewarding-punishing. Response alternatives were labeled with the following descriptors for the 7-points: extremely, quite, slightly, neither, slightly, quite, and extremely. 
Subjective norms were also measured toward "eating alone" and "eating with friends," "during the next two weeks." Two 7-point items were used to record responses in both cases. One item read, "Please indicate whether most people who are important to you approve or disapprove of your eating at a fast food restaurant sometime during the next two weeks by yourself (with friends)" and was recorded on an approve-disapprove scale. The second item read, "Please consider the people who are important in your life and what they think you should do in terms of eating at a fast food restaurant sometime during the next two weeks by yourself (with friends)," and was recorded on a should-should not eat at a fast food restaurant scale.

Past behavior was measured with responses to the item, "How many times during the past two weeks did you eat at a fast food restaurant?" The actual numbers of times one ate "alone" and "with friends" were recorded.

Intentions were measured separately by asking respondents to react to the statement, "I presently intend to eat in a fast food restaurant sometime during the next two weeks by myself (with friends)." A 7-point likely-unlikely scale was used for each item, with the same descriptors for response alternatives as employed for attitudes.

Behavioral expectations were measured separately toward "eating alone" and "eating with friends," "during the next two weeks." An 11-point item was used to record responses, with the following descriptors centered above the appropriate 11 points: 1 (no chance), 3 (slight chance), 6 (50-50; even chance), 8 (moderate chance), and 11 (certain chance).

Due to the different times of data collection and research constraints in each country, slightly different measures of self-construals were used. Therefore, analyses of attitude-intention and subjective norms-intention consistencies could only be compared within country rather than across all four country samples. Self-construals were measured by using a single individualism-collectivism item developed by Hui (1988) for the Japanese and American samples, and the 14 vertical and horizontal collectivism items for the Chinese sample (Singelis, Triandis, Bhawuk, \& Gelfand, 1995). Of the 14 items used, one item was slightly negatively correlated and was, therefore, omitted from subsequent analysis. The reliability of the remaining 13 items was .76. Finally, the Attention to Social Comparison Information scale from the revised Self-Monitoring scale by Lennox and Wolfe (1984) was used for the Italian sample (reliability $=.68$ ). Support for this operationalization of collective self can be found in Miller and Grush's (1984) study, which showed that individuals who are low in self-monitoring display a higher degree of attitude-behavior consistency than do individuals who are high in self-monitoring.

\section{Analyses}

Structural equation models were used to estimate parameters and test hypotheses (Jöreskog \& Sörbom, 1996). Figure 1 shows the variables and paths in the model. Covariance matrices were

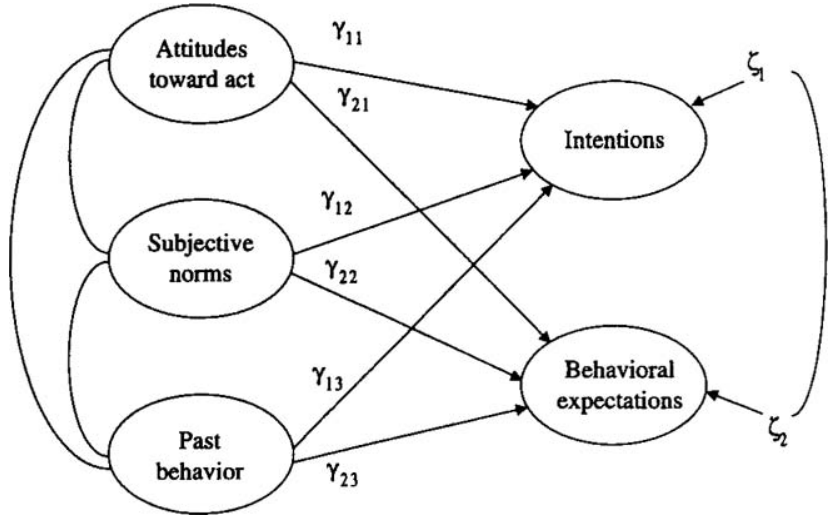

FIGURE 1 Path model to assess the effects of attitudes, subjective norms, and past behavior on intentions and behavioral expectations.

used as input to LISREL VII for the multiple sample analyses (Cudeck, 1989). All construct variances, covariances between constructs, and error variances were freely estimated in each sample, but the directional structural relations (the $\gamma_{\mathrm{ij}} \mathrm{s}$ in Figure 1) were constrained to be equal across samples, unless a coefficient in one sample differed from those in the remaining samples at a significance level of .01 or less (MacCallum, Roznowski, \& Necowitz, 1992). The pattern of invariant and noninvariant paths makes it possible to assess the generalizability of the proposed framework across the four samples. The overall goodness-of-fit of models was assessed with the chi-square test, the comparative fit index (CFI), the non-normed fit index (NNFI), and the root mean square error of approximation (RMSEA). Satisfactory fits are obtained when the chi-square test is nonsignificant, the CFI and NNFI are greater than or equal to .90 , and the RMSEA is less than or equal to .08 (see Bentler, 1990; Marsh, Balla, \& Hau, 1996; Steiger, 1990). Tests of differences in parameter estimates were performed with chi-square difference tests.

\section{RESULTS}

Reliability

Table 1 summarizes the reliabilities for the individual scales. Most scales achieve satisfactory levels of reliability. The four scales with reliabilities of .68 to .69 are close to the generally accepted standard of 70 or greater and are probably sufficient for research purposes (Nunnally, 1978).

\section{Goodness of Fit}

The model in Figure 1 was fit to the multisample data, and the procedures outlined in the Method section were followed. For eating alone, the model fit well: $\chi^{2}(4)=4.87, p \cong .30$, RMSEA $=.01, \mathrm{CFI}=1.00$, and NNFI $=.99$. Likewise, for eating with friends, the model fit well: $\chi^{2}(4)=2.73, p \equiv .60$, RMSEA $=$ $.00, \mathrm{CFI}=1.00$, and $\mathrm{NNFI}=1.00$. 
TABLE 1

Reliabilities of Scales

\begin{tabular}{lcccc}
\hline & \multicolumn{4}{c}{ Scale } \\
\cline { 2 - 5 } & $\begin{array}{l}\text { Attitude } \\
\text { (Alone) }\end{array}$ & $\begin{array}{c}\text { Attitude } \\
\text { (Friends) }\end{array}$ & $\begin{array}{c}\text { Subjective } \\
\text { Norms (Alone) }\end{array}$ & $\begin{array}{c}\text { Subjective } \\
\text { Norms (Friends) }\end{array}$ \\
\hline Chinese & .74 & .78 & .76 & .79 \\
Italians & .69 & .74 & .82 & .79 \\
Japanese & .72 & .80 & .68 & .78 \\
Americans & .69 & .78 & .68 & .71 \\
\hline
\end{tabular}

\section{Parameter Estimates}

The findings in Tables 2 and 3 show that, consistent with expectations, attitudes and past behavior significantly predicted intentions and behavioral expectations, except for the Chinese, where attitudes failed to significantly predict intentions. Likewise as forecast, subjective norms were stronger predictors of intentions and expectations for eating with friends than for eating alone. Indeed, with one exception, subjective norms failed to significantly predict intentions and behavioral expectations for eating alone (Table 2), but were significant predictors in each case for eating with friends (Table 3 ). The lone exception occurs for the effect of subjective norms on intentions for eating alone, where the impact was significant for Chinese $\left(\gamma_{12}=.17, p<.001\right)$.

Tables 2 and 3 further show that the magnitudes of effects were generally greater for Americans than for all other groups, for the impact of attitudes on both intentions and behavioral expectations, and for the impact of past behavior on both intentions and behavioral expectations. Similar comparisons for Italians versus both Japanese and Chinese revealed that sometimes coefficients were greater, sometimes less, in magnitude. In addition, the effects of subjective norms on intentions and behavioral expectations were generally greater for Chinese than for Americans and Italians, as hypothesized, whereas these paths were of equal magnitude for Americans, Italians, and Japanese, contrary to predictions. Thus, the hypotheses predicting larger effects for Western versus Eastern cultures for the impact of attitudes and past behavior, and larger effects for Eastern versus Western cultures, for the impact of subjective norms, received mixed support.

It should be noted that the aforementioned confirmations of predictions under the TRA were achieved even after controlling for past behavior. Hence, the influences of attitudes and subjective norms, which reflect deliberative processes, occur even after taking into account any habitual or mindless effects captured by measures of past behavior.

\section{Variance Explained}

Table 4 summarizes the amount of explained variance in intentions and behavioral expectations across cultural groups. As hypothesized, greater amounts of explained variance occur for Western (American, Italian), as opposed to Eastern (Japanese, Chinese), cultures. In most cases, the greatest amounts of explained variance occurred for Americans, as hypothesized.

Notice, too, that more variance was explained in intentions than behavioral expectations for eating alone, whereas less variance was accounted for in intentions than behavioral expectations for eating with friends. These findings are consistent with the claim that eating alone is guided relatively more by individual than social criteria, whereas eating with friends is governed relatively more by social than individual criteria. These results complement the findings noted previously for the differential effects of subjective norms across the two eating contexts.

\section{Past Behavior}

Finally, Table 4 shows the effect of adding past behavior to the theory of reasoned action. Past behavior generally adds considerably to the amount of variance accounted for in intentions and expectations. The addition of past behavior also generally reduced the impact of attitudes and subjective norms on intentions and expectations, compared to the tests of the theory of reasoned action. Nevertheless, the pattern of results for paths, when comparing the theory of reasoned action to the theory of reasoned action augmented by past be-

TABLE 2

Summary of Path Coefficients for Eating Alone

\begin{tabular}{lllll}
\hline Path & Americans $^{\mathrm{a}}$ & Italians $^{\mathrm{b}}$ & Japanese $^{\mathrm{c}}$ & Chinese $^{\mathrm{d}}$ \\
\hline Attitudes $\rightarrow$ Intentions & $.44\left(.34^{* * *}\right)$ & $.34\left(.16^{* * *}\right)$ & $.27\left(.19^{* * *}\right)$ & $.11(.07)$ \\
Subjective norms $\rightarrow$ Intentions & $.03(.03)$ & $.04(.03)$ & $.04(.03)$ & $.26\left(.17^{* * *}\right)$ \\
Past behavior $\rightarrow$ Intentions & $.40\left(.53^{* * *}\right)$ & $.22\left(.10^{* *}\right)$ & $.33\left(.50^{* * *}\right)$ & $.19\left(.11^{* * *}\right)$ \\
Attitudes $\rightarrow$ Expectations & $.37\left(.40^{* * *}\right)$ & $.23\left(.13^{* *}\right)$ & $.22\left(.20^{* * *}\right)$ & $.15\left(.11^{*}\right)$ \\
Subjective norms $\rightarrow$ Expectations & $.04(.05)$ & $.06(.05)$ & $.05(.05)$ & $.05(.04)$ \\
Past behavior $\rightarrow$ Expectations & $.47\left(.85^{* * *}\right)$ & $.34\left(.18^{* * *}\right)$ & $.36\left(.72^{* * *}\right)$ & $.34\left(.24^{* * *}\right)$ \\
\hline
\end{tabular}

Note. Unstandardized parameters in parentheses; standardized parameters not in parentheses.

${ }^{\mathrm{a}} N=246 .{ }^{\mathrm{b}} N=123 .{ }^{\mathrm{c}} N=419 .{ }^{\mathrm{d}} N=264$.

${ }^{*} p<.05 .{ }^{* *} p<.01 .{ }^{* * *} p<.001$. 
TABLE 3

Summary of Path Coefficients for Eating With Friends

\begin{tabular}{|c|c|c|c|c|}
\hline Path & Americans ${ }^{\mathrm{a}}$ & Italians ${ }^{\mathrm{b}}$ & Japanese $e^{\mathfrak{c}}$ & Chinese \\
\hline Attitudes $\rightarrow$ Intentions & $.34(.22 * * *)$ & $.27(.09 * * *)$ & $.19\left(.11^{* * *}\right)$ & $.06(.03)$ \\
\hline Subjective norms $\rightarrow$ Intentions & $.07\left(.05^{*}\right)$ & $.08\left(.05^{*}\right)$ & $.08\left(.05^{*}\right)$ & $.30(.21 * * *)$ \\
\hline Past behavior $\rightarrow$ Intentions & $.30(.29 * * *)$ & $.39\left(.13^{* * *}\right)$ & $.23(.13 * * *)$ & $.10(.07)$ \\
\hline Attitudes $\rightarrow$ Expectations & $.33(.29 * * *)$ & $.19\left(.09^{*}\right)$ & $.30(.25 * * *)$ & $.02(.02)$ \\
\hline Subjective norms $\rightarrow$ Expectations & $.08(.09 * *)$ & $.10\left(.09^{* *}\right)$ & $.10(.09 * *)$ & $.13\left(.13^{*}\right)$ \\
\hline Past behavior $\rightarrow$ Expectations & $.41\left(.57^{* * *}\right)$ & $.47(.22 * * *)$ & $.23\left(.19^{* * *}\right)$ & $.13\left(.13^{*}\right)$ \\
\hline
\end{tabular}

Note. Unstandardized parameters in parentheses; standardized parameters not in parentheses.

${ }^{\mathrm{a}} N=246 .{ }^{\mathrm{b}} N=123 .{ }^{\mathrm{c}} N=419 .{ }^{\mathrm{d}} \mathrm{N}=264$

${ }^{*} p<.05{ }^{* *} p<.01 .{ }^{* * *} p<.001$.

TABLE 4

Variation Accounted for in Intentions and Behavioral Expectations

\begin{tabular}{lcccc}
\hline & Americans $^{\mathrm{a}}$ & Italians $^{\mathrm{b}}$ & Japanese $^{\mathrm{c}}$ & Chinese $^{\mathrm{d}}$ \\
\hline Eating alone & & & & $.17(.08)$ \\
$\quad$ Intentions & $.58(.33)$ & $.27(.16)$ & $.24(.10)$ & $.14(.03)$ \\
$\quad$ Expectations & $.46(.28)$ & $.24(.09)$ & $.23(.09)$ & $.13(.02)$ \\
Eating with friends & & & $.05)$ & $.04(.01)$ \\
$\quad$ Intentions & $.30(.19)$ & $.31(.07)$ & $.19(.11)$ & $.08)$ \\
$\quad$ Expectations & $.39(.21)$ & $.33(.08)$ & & .05 \\
\hline
\end{tabular}

Note. Numbers not in parentheses are for the theory of reasoned action with past behavior included as a predictor. Numbers in parentheses are for the theory of reasoned action (i.e., past behavior is not included as a predictor).

${ }^{\mathrm{a}} N=246 .{ }^{\mathrm{b}} N=123 .{ }^{\mathrm{c}} N=419 .{ }^{\mathrm{d}} \mathrm{N}=264$.

havior, lead to the same substantive conclusions as those shown in Tables 2 and 3.

\section{Structured Means}

Tables 5 and 6 present the results for tests of hypotheses on the mean levels of the variables shown in Figure 1. The first findings to note are that Americans exhibit means on attitudes, subjective norms, past behavior, intentions, and behavioral expectations that are, in most cases, greater than, and in the remaining cases, equal to, the corresponding means for Italians, Japanese, and Chinese. In fact, Americans scored higher on all five variables than did the Japanese. The Japanese, in turn, scored the lowest among all groups on nearly every variable. The major exception occurs for attitudes, where the Japanese actually had stronger attitudes than did Italians toward eating alone and eating with friends.

\section{Within-Culture Variation}

Within culture variation of the TRA was tested by comparing the correlation between attitude intention and subjective norms intention in a split sample based on self-construal measures for each country. Table 7 shows, as hypothesized, that both Chinese and Americans who are high in collective self also tended to show higher subjective norms-intention consistencies than did individuals who are low in collective self. For Americans, this correspondence became even stronger in the situation of eating with friends than in eating alone. Table 7 shows that the interaction between culture (high collective self) and situation (eating with friends) created the biggest impact in the subjective norms intention correspondence than did either culture or situation alone. Surprisingly, however, the Japanese sample showed no differences between individuals who are high or low in collectivist self or situation. Also, the Italian sample failed to show the hypothesized pattern. That is, individuals who were high in self-monitoring actually showed lower correspondence in the subjective norms-intention relation than did low self-monitors. This result could be attributed to the fact that the attention to social comparison information items from the revised self-monitoring scale do not capture the same dimension of self-construal as that previously tested by Miller and Grush (1984).

\section{DISCUSSION}

From one perspective, the findings demonstrate that the TRA is remarkably robust. Attitudes and subjective norms significantly predict intentions to act, according to theory, for both multiple Western (American, Italian) and Eastern (Chinese, Japanese) cultures. Furthermore, predictions under the TRA were sustained even after controlling for the effects of past behavior. The latter finding suggests that the decision to patronize fast food restaurants is a rational process wherein consumers take into account their attitudes and felt 
TABLE 5

Strunturad Means (Eatina Alone)

\begin{tabular}{|c|c|c|c|c|c|}
\hline Country & Attitude & $\begin{array}{c}\text { Past } \\
\text { Behavior }\end{array}$ & $\begin{array}{c}\text { Subjective } \\
\text { Norm }\end{array}$ & Intentions & Expectations \\
\hline American ${ }^{2}$ & $.00^{\mathrm{b}}$ & $.00^{b}$ & $.00^{\mathrm{b}}$ & $.00^{\mathrm{b}}$ & $.00^{\mathrm{b}}$ \\
\hline Italian ${ }^{6}$ & $-1.57 * * *$ & .48 & -.15 & $-.54^{*}$ & $-1.60^{* * *}$ \\
\hline Japanese $^{d}$ & $-1.18^{* * *}$ & $-.79 * * *$ & $-.62 * * *$ & $-1.21 * * *$ & $-1.65^{* * *}$ \\
\hline Chinese $^{e}$ & .22 & $1.06^{* * *}$ & .16 & .22 & $-.66^{*}$ \\
\hline Chinese & $.00^{\mathrm{b}}$ & $.00^{b}$ & $.00^{\mathrm{b}}$ & $.00^{\mathrm{b}}$ & $.00^{\mathrm{b}}$ \\
\hline Italian & $-1.79 * * *$ & -.58 & $-.31 *$ & -.77 & $-.95 * * *$ \\
\hline Japanese & $-1.40^{* * *}$ & $-1.85 * * *$ & $-.79 * * *$ & $-1.43 * * *$ & $-.99 * * *$ \\
\hline Italian & $.00^{\mathrm{b}}$ & $.00^{\mathrm{b}}$ & $.00^{\mathrm{b}}$ & $.00^{\mathrm{b}}$ & $.00^{\mathrm{b}}$ \\
\hline Japanese & $.39 *$ & $-1.27^{* * *}$ & $-.48^{* * *}$ & $-.66 * *$ & -.04 \\
\hline
\end{tabular}

${ }^{\mathrm{a}} N=246 .{ }^{\mathrm{D}}$ Mean fixed to zero as baseline. ${ }^{\mathrm{c}} N=123 .{ }^{\mathrm{d}} N=419 .{ }^{\mathrm{e}} N=264$

${ }^{*} p<.05 .{ }^{* *} p<.01 .{ }^{* * *} p<.001$

TABLE 6

Structured Means (Eating With Friends)

\begin{tabular}{lccccr}
\hline Country & Attitude & $\begin{array}{c}\text { Past } \\
\text { Behavior }\end{array}$ & $\begin{array}{c}\text { Subjective } \\
\text { Norm }\end{array}$ & Intentions & Expectations \\
\hline American $^{\mathrm{a}}$ & $.00^{\mathrm{b}}$ & $.00^{\mathrm{b}}$ & $.00^{\mathrm{b}}$ & $.00^{\mathrm{b}}$ & $.00^{\mathrm{b}}$ \\
Italian $^{\mathrm{c}}$ & $-.75^{* * *}$ & .65 & -.22 & -.42 & $-1.95^{* * *}$ \\
Japanese $^{\mathrm{d}}$ & $-.26^{*}$ & $-.47^{*}$ & $-.70^{* * *}$ & $-.54^{* * *}$ & $-1.02^{* * *}$ \\
Chinese $^{\mathrm{e}}$ & .27 & -.01 & .18 & $-.50^{* *}$ & $-1.80^{* * *}$ \\
Chinese & $.00^{\mathrm{b}}$ & $.00^{\mathrm{b}}$ & $.00^{\mathrm{b}}$ & $.00^{\mathrm{b}}$ & $.00^{\mathrm{b}}$ \\
Italian & $-1.02^{* * *}$ & .66 & $-.38^{*}$ & .08 & -.15 \\
Japanese & $-.53^{* * *}$ & $-.46^{*}$ & $-.85^{* * *}$ & -.04 & $.78^{* * *}$ \\
Italian & $.00^{\mathrm{b}}$ & $.00^{\mathrm{b}}$ & $.00^{\mathrm{b}}$ & $.00^{\mathrm{b}}$ & $.00^{\mathrm{b}}$ \\
Japanese & $.48^{*}$ & $-1.11^{* *}$ & $-.46^{* *}$ & -.12 & $.93^{* * *}$ \\
\hline
\end{tabular}

${ }^{\mathrm{a}} N=246 .{ }^{\mathrm{b}} \mathrm{Mean}$ fixed to zero as baseline ${ }^{\mathrm{c}} N=123 .{ }^{\mathrm{d}} N=419 .{ }^{\mathrm{e}} N=264$.

${ }^{*} p<.05 .{ }^{* *} p<.01 .{ }^{* * *} p<.001$.

normative pressure, doing so despite prior learning and tendencies to act habitually.

However, it is important to point out that the functioning of the processes implied by the TRA were contingent on certain social and cultural processes. Subjective norms were found to influence decision making only for the case of eating with friends. Apparently for eating alone, the decision to patronize fast food restaurants by students in the Western and Eastern cultures under study is a function primarily of the tastes of consumers (i.e., their attitudes or preferences) and not felt normative imperatives. Eating alone in a fast food restaurant most likely has little social ramifications; at least, direct pressures from peers and significant others are not likely to come to bear on decisions to eat alone in fast food restaurants for most students. Hence, one's attitudes are the primary factors governing patronage decisions for eating alone. By contrast, eating with friends is, by definition, a social act with the opportunity for direct experience of social pressure. Here, for all the cultural groups under investigation, attitudes and subjective norms had parallel, independent effects on intentions to eat with friends in fast food restaurants, and subjective norms captured the effects of peer pressure.

Significant effects of attitudes and past behavior on decisions were found generally across all four groups. Neverthe- less, a number of differences across groups should be mentioned because these provide insights into the generalizability of the TRA.

First, higher levels of explained variance in decisions occurred for the Western, as opposed to Eastern, cultures. Moreover, the magnitudes of effects from attitudes, subjective norms, and past behavior on decisions were stronger in all cases for Americans than for the other respondents. In addition, as revealed by the tests of structured means, Americans generally scored significantly higher on the mean levels of all variables under examination. These results suggest that the TRA, although applicable across the cultures under study, works best for Americans. This is not surprising, perhaps, because the TRA was developed in the United States and has been most frequently tested there. The question can be raised for future research whether other variables need to be introduced into the TRA to explicitly account for differences between independent- and interdependent-based cultures. Of course, more testing of the TRA is needed not only across more instances of these broad cultural tendencies, but also for other products and services.

In addition to intentions, we examined behavioral expectations as functions of attitudes, subjective norms, and past behavior. Intentions are thought to take into account internal 
TABLE 7

Subjective Norms-Intention (SN-INT) Consistencies Between Individuals of High- Versus Low-Collective Self

\begin{tabular}{|c|c|c|c|c|c|c|c|c|}
\hline \multirow[b]{2}{*}{ Decision Context } & \multicolumn{2}{|c|}{ Americans $^{2}$} & \multicolumn{2}{|c|}{ Italians ${ }^{\mathrm{b}}$} & \multicolumn{2}{|c|}{ Japanese } & \multicolumn{2}{|c|}{ Chinese $^{c}$} \\
\hline & Low Coll ${ }^{d}$ & High Coll & Low ATSCr & High $A T S C I^{B}$ & Low Coll ${ }^{\mathrm{h}}$ & High Coll & Low Coll & High Coll $^{\mathbf{k}}$ \\
\hline \multicolumn{9}{|l|}{ Eating alone } \\
\hline SN-INT & .07 & $.33^{*}$ & $.41^{*}$ & .14 & .10 & .08 & $.30^{*}$ & $.33^{*}$ \\
\hline \multicolumn{9}{|l|}{ Eating with friends } \\
\hline SN-INT & .11 & $.39 *$ & .21 & .18 & .10 & .12 & $.32^{*}$ & $.35^{*}$ \\
\hline
\end{tabular}

Note. low coll = low collective; high coll $=$ high collective; $\mathrm{ATSCI}=$ attention to social comparison information items.

${ }^{\mathrm{s}} \mathrm{Single}$ item measure of collectivism (Hui, 1988). ${ }^{\mathrm{b}}$ Sum of 13 ATSCI items (Lennox \& Wolfe, 1984). ${ }^{\mathrm{c}}$ Sum of seven vertical and six horizontal collectivism items (Singelis, Triandis, Bhawuk, \& Gelfand, 1995). ${ }^{\mathrm{d}} n=131 .{ }^{\mathrm{e}} n=114 .{ }^{\mathrm{f}} n=64 .{ }^{\mathrm{g}} n=59 .{ }^{\mathrm{h}} n=176 .{ }^{\mathrm{i}} n=242 .{ }^{\mathrm{j}} n=$ 129. ${ }^{k} n=129$.

$* p<.001$.

predispositions for acting, such as is reflected in attitudes and subjective norms, whereas behavioral expectations are thought to reflect not only internal predispositions, but also assessments of external impediments (Warshaw \& Davis, 1985). Although intentions and behavioral expectations were both functions of attitudes, subjective norms, and past behavior, the pattern of results showed interesting differences. For eating alone, more variance was explained in intentions than behavioral expectations for each of the cultural groups (Table 4). For eating with friends, less variance was explained in intentions than behavioral expectations across cultural groups (Table 4). Inspection of parameter estimates suggests that the differences found under eating with friends is explainable by the relatively stronger effects on expectations, in comparison to intentions, for all predictors (compare unstandardized parameter estimates in Table 3 ). No consistent explanation can be gleaned from Table 2 for the differences found under eating alone. At least for eating with friends, it seems that behavioral expectations better transform the information provided by attitudes, subjective norms, and past behavior into a decision than do intentions, perhaps because of the incorporation of the contingencies implied by the social setting.

In general, because of the small sample sizes in the split cells, between-cell differences (i.e., high vs. low collectivist and eating alone vs. eating with friends) did not achieve statistical significance. Nevertheless, the pattern of relations in Table 7 proves informative. That is, in all four country samples, individuals who are higher in collectivism showed increasing subjective norm-intention consistencies in moving from the situation of eating alone versus eating with friends, whereas those who are lower in collectivism do not show such changes. This finding is consistent with extant theory on individualism and collectivism. For example, Kim (1994) suggested that a defining attribute of individualism is the emphasis on abstract principles. It is a process by which core values and characteristics of a group are abstracted from a specific context and person. Researchers have often found that people from the United States describe their personalities in an abstract and context-free manner, which is in sharp con- trast to the Chinese or Japanese views, which are mainly concrete, relational, and context-sensitive (Markus \& Kitayama, 1991; Shweder \& Bourne, 1984).

A surprising finding in Table 7 is the high subjective norm-intention consistencies across all situations (eating alone vs. eating with friends and low vs. high collectivists) for the Chinese sample and the lack of correspondence for the Japanese sample. There are two plausible explanations for this difference. That is, there are significant differences in the frequencies and situations of eating at fast food restaurants between the two countries. Table 8 summarizes the number of times respondents eat in fast food restaurants in a typical 2-week period in both situations, alone and with friends. Judging from Table 8, we conclude that Chinese respondents eat at fast food restaurants about three times more frequently than Japanese respondents. In comparison, the Japanese respondents rarely eat at fast food restaurants and almost never eat there alone. Therefore, the lack of subjective norm-intention consistencies in the Japanese sample could be attributed to the lack of consumption experiences for the Japanese respondents.

This study has a number of weaknesses that should be pointed out. First, the research rests on a survey design; an experimental investigation of the hypotheses would provide more confidence in the processes under study. Second, only four samples were obtained across the two cultural patterns; replications are needed across other cultural groups. Third, as mentioned earlier, replications are needed across a variety of consumer goods and services. Fourth, it would be desirable to revise the TRA so as to more explicitly accommodate processes underlying differ-

TABLE 8

Frequencies of Actual Fast Food Restaurant Visits in a Typical 2-Week Period

\begin{tabular}{lllll}
\hline Decision Context & Americans $^{\mathrm{a}}$ & Italians $^{\mathrm{b}}$ & Japanese $^{\mathrm{c}}$ & Chinese $^{\mathrm{d}}$ \\
\hline Eating alone & $1.12(32 \%)$ & $2.54(40 \%)$ & $0.29(15 \%)$ & $2.30(52 \%)$ \\
Eating with friends & $2.36(68 \%)$ & $3.77(60 \%)$ & $1.58(85 \%)$ & $2.10(48 \%)$ \\
Total & $3.48(100 \%)$ & $6.31(100 \%)$ & $1.87(100 \%)$ & $4.40(100 \%)$ \\
\hline
\end{tabular}

${ }^{\mathrm{a}} N=246 .{ }^{\mathrm{b}} N=123 .{ }^{\mathrm{c}} N=419 .{ }^{\mathrm{d}} N=262$. 
ences between independent- and interdependent-based cultures. Despite the previously noted limitations, this study did provide some control in the testing of the TRA by examining four groups and incorporating past behavior as a covariate and predictor. To the best of our knowledge, this is the first study to examine the generalizability of the TRA to this extent. The TRA appears to be a relatively general model for explaining consumer behavior across different cultural groups.

\section{REFERENCES}

Ajzen, I. (1988). Attitudes, personality, and behavior. Chicago: Dorsey.

Ajzen, I. (1991). The theory of planned behavior. Organizational Behavior and Human Decision Processes, 50, 179-211.

Ajzen, L., \& Fishbein, M. (1980). Understanding attitudes and predicting social behavior. Englewood Cliffs, NJ: Prentice Hall.

Bagozzi, R. P. (1981). Attitudes, intentions, and behavior: A test of some key hypotheses. Journal of Personality and Social Psychology, 41, $607-627$.

Bentler, P. M. (1990). Comparative fit indexes in structural models. Psychological Bulletin, 107, 238-246.

Bentler, P. M., \& Speckart, G. (1979). Models of attitude-behavior relations. Psychological Review, 86, 452-464.

Berry, J. W., Poortinga, Y. H., Segall, M. H., \& Dasen, P. R. (1992). Cross-cultural psychology: Research and applications. Cambridge, England: Cambridge University Press.

Bontempo, R. N., \& Rivero, J. C. (1990), Cultural variation in cognition: The role of self-concept and the attitude-behavior link. Unpublished manuscript.

Brislin, R. W. (1986). The wording and translation of research instruments. In W. J. Lonner \& J. W. Berry (Eds.), Field methods in cross-cultural research (pp. 137-164). Beverly Hills, CA: Sage.

Brockner, J., \& Chen, Y. (1996). The moderating roles of self-esteem and self-construal in reaction to a threat to the self: Evidence from the People's Republic of China and the United States. Journal of Personality and Social Psychology, 71, 603-615.

Cudeck, R. (1989). Analysis of correlation matrices using covariance structure models. Psychological Bulletin, 105, 317-327.

Eagly, A. H., \& Chaiken, S. (1993). The psychology of attitudes. Fort Worth, TX: Harcourt Brace.

Fishbein, M., \& Ajzen, I. (1975). Belief, attitude, intention, and behavior: An introduction to theory and research. Reading, MA: Addison-Wesley.

Fredericks, A. J., \& Dossett, D. L. (1983). Attitude-behavior relations: A comparison of the Fishbein-Ajzen and the Bentler-Speckart models. Journal of Personality and Social Psychology, 45, 501-512.

Hui, C. H. (1988). Measurement of individualism-collectivism. Journal for Research in Personality, 22, 17-36.

Jöreskog, K. G., \& Sörbom, D. (1996). LISREL VII user's reference guide. Chicago: Scientific Software.

Kim, U. (1994). Theoretical and methodological approaches to the study of collectivism and individualism. In U. Kim, H. C. Triandis, C. Kagitcibasi, S. C. Choi, \& J. Yoon (Eds.), Individualism and collectivism: Theory, method, and application (pp. 19-40). Thousand Oaks, CA: Sage.

Lee, C., \& Green, R. T. (1991). Cross-cultural examination of the Fishbein behavioral intentions model. Journal of International Business Studies, 22, 289-305.

Lennox, R. D., \& Wolfe, R. N. (1984). Revision of the self-monitoring scale. Journal of Personality and Social Psychology, 46, 1349-1369.

Lutz, R. J. (1977). An experimental investigation of causal relations among cognitions, affect, and behavioral intentions. Journal of Consumer Research, 3, 197-208.
MacCallum, R. C., Roznowski, M., \& Necowitz, L. B. (1992). Model modifications in covariance structure analysis: The problem of capitalization on chance. Psychological Bulletin, 111, 490-504.

Markus, H. R., \& Kitayama, S. (1991). Culture and the self: Implications for cognition, emotion, and motivation. Psychological Review, 98, 224-253.

Marsh, H. W., Balla, J. R., \& Hau, K.-T. (1996). An evaluation of incremental fit indices: A clarification of mathematical and empirical properties. In G. A. Marcoulides \& R. E. Schumacker (Eds.), Advanced structural equation modeling: Issues and techniques (pp. 315-353). Mahwah, NJ: Lawrence Erlbaum Associates, Inc.

Matsumoto, D. (1996). Culture and psychology. Pacific Grove, CA: Brooks/Cole

Miller, J. G. (1994). Cultural diversity in the morality of caring: Individually-oriented versus duty-oriented interpersonal codes. Cross-Cultural Research, 28, 3-39.

Miller, L. E., \& Grush, J. E. (1984). Individual differences in attitudinal versus normative determination of behavior. Journal of Experimental Social Psychology, 22, 190-202.

Nunnally, J. C. (1978). Psychometric theory (2nd ed.). New York: McGraw-Hill.

Ryan, M. J., \& Bonfield, E. H. (1980). Fishbein's intentions model: A test of external and pragmatic validity. Journal of Marketing, 44, 82-95.

Sheppard, B. H., Hartwick, J., \& Warshaw, P. R. (1988). The theory of reasoned action: A meta-analysis of past research with recommendations for modifications and future research. Journal of Consumer Research, $15,325-343$

Shweder, R. A., \& Bourne, E. D. (1984). Does the concept of the person vary cross-culturally? In R. A. Shweder \& R. A. Levine (Eds.), Cuiture theory: Essays on mind, self, and emotion (pp. 158-199). New York: Cambridge University Press.

Singelis, T. M., Triandis, H. C., Bhawuk, D. P. S., \& Gelfand, M. J. (1995). Horizontal and vertical dimensions of individualism and collectivism: A theoretical and measurement refinement. Cross-Cultural Research, $29,240-275$.

Steiger, J. H. (1990). Structural model evaluation and modification: An interval estimation approach. Multivariate Behavioral Research, 25 , $173-180$

Trafimow, D., \& Finlay, K. A. (1996). The importance of subjective norms for a minority of people: Between-subjects and within-subjects analyses. Personality and Social Psychology Bulletin, 22, 820-828.

Trafimow, D., Triandis, H. C., \& Goto, S. (1991). Some tests of the distinction between the private self and the collective self. Journal of Personality and Social Psychology, 60, 649-655.

Triandis, H. C. (1989). The self and social behavior in differing cultural contexts. Psychological Review, 96, 506-520.

Triandis, H. C. (1994a). Culture and social behavior. New York: McGraw-Hill.

Triandis, H. C. (1994b). Theoretical and methodological approaches. In U. Kim, H. C. Triandis, C. Kagitcibasi, S. Choi, \& G. Yoon (Eds.), Individualism and collectivism (pp. 41-51). Thousand Oaks, CA: Sage.

Triandis, H. C., \& Bhawuk, D. (1997). Culture theory and the meaning of relatedness. In P.C. Earley \& M. Erez (Eds.), New perspectives on international industriaVorganizational psychology (pp. 13-52). San Francisco: The New Lexington Press.

Warshaw, P. R., \& Davis, F. D. (1985). Disentangling behavioral intention and behavioral expectation. Journal of Experimental Social Psychology, 21, 213-228.

Accepted by Durairaj Maheswaran. 